\title{
Glaser mot Strauss - två utvecklingar av grounded theory
}

\author{
MINNA SALMINEN-KARLSSSON
}

Artikeln presenterar och diskuterar utvecklingen av forskningsmetoden grounded theory. Två varianter presenteras, där Strauss \& Corbins (1990) presentation av metoden kontrasteras mot den ursprungliga presentationen av Glaser \& Strauss $(1967)$ och Glasers $(1978,1992)$ vidareutveckling av denna. Framför allt diskuteras hur forskarens roll uppfattas i de olika varianterna. De olika utvecklingarna av grounded theory uppfattas som tillhörande delvis olika forskningsparadigm, vilket kräver en ökad medvetenhet av forskaren vid metodval.

\section{Inledning}

Grounded theory (GT) tillhör de kvalitativa metoderna som oftast presenteras på metodkurser för såväl beteendevetenskapliga som vårdvetenskapliga forskarstudenter. Som litteratur används oftast Glaser \& Strauss (1967) och Strauss \& Corbin (1990), som har blivit nästan normgivande för hur stringent kvalitativ beteendevetenskaplig forskning skall bedrivas.

Strauss \& Corbins (1990) bok kan tänkas ha bidragit till detta intresse för grounded

Minna Salminen-Karlsson, fil. dr. i pedagogik och forskarassistent vid Tema teknik och social förändring, Linköpings universitet. theory. Tydligheten i dess anvisningar och rekommendationer är tilltalande, inte minst för dem som inte är erfarna forskare. Att metoden sedan i praktiken, om man följer receptet till punkt och pricka, är både komplicerad och arbetsam, bevittnar Guvå \& Hylander (1998). Troligen är det därför som det inom den beteendevetenskapliga forskningen finns ett stort antal uppsatser och forskningsprojekt med ett "grounded theory -inspirerat« angreppssätt, men knappast någon som egentligen har följt metoden så som Strauss \& Corbin föreskriver den. Denna tendens är tydlig även i amerikansk forskning. T.ex. konstaterar Locke (1996) efter sin genomgång av American Journal 
of Management att artiklar som anger sig använda en "grounded theory approach" ofta inte närmare specificerar sina procedurer och att när de gör det, kan dessa beskrivningar vissa forskningspraktiker som egentligen är motsatta mot vad grounded theory implicerar. Genom att mycket olika slag av kvalitativ forskning kallas för grounded theory, blir inte metoden i sig tydlig, och det är kanske också därför som diskussionen om dess grundvalar, möjligheter och problem inte är särskilt framträdande.

Denna artikel grundar sig på reflektioner över grounded theory i den form som den presenteras av Strauss \& Corbin (1990) och problematiserar vissa aspekter av den. Dessa aspekter sätts i relation till den utvecklingslinje som Glasers arbete representerar. Syftet är att visa att grounded theory inte är ett enkelt och oproblematiskt begrepp, utan att úê finms ivå olika uiveckiingsiinjer, och att den linje som Strauss \& Corbin representerar har behäftats med vissa problem i sin övergång till en mer konstruktivistisk utgångspunkt.

\section{Grounded theory i begynnelsen}

Grounded theory presenterades av Glaser \& Strauss 1967 i boken The Discovery of Grounded theory. Där polemiserade de mot den förhärskande sociologiska forskningsinriktningen och presenterade ett eget, kvalitativt inriktat, alternativ. Glaser \& Strauss (1967) hävdade att det förhärskande sättet att göra forskning resulterade i en avgrund mellan teorier och den empiriska verkligheten. De ansåg att forskningen borde presentera resultat som även var praktiskt använd- bara, vilket de rådande teoribyggnaderna enligt dem inte var. Som en lösning presenterade de procedurer som kunde företas med ett kvalitativt material, för att i slutändan komma fram till en välformulerad och praktiskt användbar teori om något mikrosociologiskt fenomen. Visserligen uteslöt de inte att kvantitativt material kunde användas i skapandet av en teori och visserligen var en av målsättningarna att formulera teorin med begrepp som senare kunde behandlas kvantitativt, men deras tankar var avsedda och användes också för att främja kvalitativ forskning i ett förhärskande kvantitativt paradigm inom den amerikanska sociologin.

Glaser \& Strauss (1967) skriver om två nivåer av grounded theory: den substantiva, som uttalar sig om en speciell verksamhet, och den formella, som uttalar sig mer övergripande. En formell teori kan, enligt Giaser $\tilde{\alpha}$ Strauss byggas upp genom att man helt enkelt ersätter termer som har direkt med det studerade området att göra med mer generella termer. Detta anser Glaser \& Strauss dock vara väl spekulativt. Det överlägsna sättet att bygga formell teori är att utifrån ett underlag av substantiva teorier från flera olika områden göra en sammanfattande teori. Glaser (1978) som utvecklar resonemanget poängterar att även den mest övergripande formella teorin bör kunna härledas till empiriska studier samt att den är en slutprodukt av ett antal substantiva teorier.

Glaser \& Strauss (1967) kallade sin metod constant comparative method - det empiriska materialet skulle delas i småbitar, bitarna skulle kodas och kontinuerligt jämföras med varandra för att upptäcka mönster i materialet. Metoden kunde uppfattas 
som ett »objektivt« sätt att hantera kvalitativa data, och kunde därför vara tilltalande för forskare som inskolats i den positivistiska forskningstraditionen. Den kvalitativa empirin förvandlas till synbarligen objektiva koder och kategorier. Det är detta som i allmänhet ses som kännetecknet på grounded theory.

Locke (1996) räknar upp nyheter som grounded theory innebar i dåtida sociologisk forskning: inspiration för forskare-även för dem som var i början av sin bana - att använda sin intellektuella fantasi och kreativitet i utvecklandet av teorier inom sina intresseområden, metoder med vilka detta kunde göras, kriterier för utvärdering av den upptäckta - i stället för testade - teorin och introduktionen av ett annat begrepp, generering, för att balansera vikten av begreppet verifiering i forskningsartiklar och -rapporter (Locke, 1996, s. 239).

Grounded theory är alltså inte en teori, utan en metod för att komma fram till en teori, som också kallas grounded theory. Metoden grounded theory är inte i första hand avsedd för undersökning av stabila strukturer. Den ger sig ut för att undersöka processer och inte statiska tillstånd, d.v.s. den förklarar förändring. Eftersom grunderna ligger inom symbolisk interaktionism, är ändamålet att förstå människornas konstruktion av sin sociala verklighet. Med hjälp av denna förståelse kan man förklara deras beteende och forskningsresultatet, en "grounded theory", ger en beskrivande förklaringav dennaverklighetskonstruktion och hur den manifesteras i beteendet. I sin ursprungsform och i de flesta empiriska studier rör sig grounded theory på det mellanmänskligt interaktionella planet, även om
Glaser (1978) också påpekar att socialpsykologiska och strukturella processer är beroende av varandra och att metoden grounded theory skall kunna användas för undersökning av dem båda.

Grundantagandet är att det i den studerade gruppen finns en oartikulerad basproblematik som hanteras med en grundläggande social process och det är denna process som den grundade teorin skall göra en beskrivning av. Forskaren skall inte i utgångsläget ha någon egen uppfattning om vilken denna grundläggande problematik eller sociala process kan tänkas vara, utan skall helt enkelt bege sig till den grupp människor som hon är intresserad av, börja observera och låta sedan forskningsfrågan och datainsamlingen styras av vad hon hittar i fältet. Det är forskningssubjektens och inte forskarens problematik som skall vara styrande i forskningsprocessen.

Datainsamlingen skall också vara styrd av den uppkommande teorin, så att forskaren samlar in de data som behövs för att successivt svara på frågeställningen. Denna s.k. theoretical sampling presenteras som motsats till en modell där undersökningsgruppen har valts ut före insamlandet av empirin. (Denna förnuftiga tanke kan dock vara problematisk att realisera i praktiken.)

Beskrivningen, den färdiga teorin, skall vara konceptualiserad och tät. Denna beskrivning eller teori skall vara så konceptuell att den går att transferera till andra områden där liknande problematik förekommer. Samtidigt skall den vara igenkännbar och praktiskt användbar för den beforskade gruppen. Grounded theory presenterar ett svar på en fråga - tvetydigheter och konstruktioner där flera svar överlappar eller 
belyser frågan från olika håll är inte grounded theory. I stället rekommenderar Glaser \& Strauss (1967) forskaren att spara på resultat som inte ryms inom en teoris ram till senare artiklar om samma område.

Grounded theory har kritiserats (t.ex. av Layder, 1993; Alvesson \& Sköldberg, 1994) just för de två aspekterna som begränsar de möjliga forskningsfrågorna och möjligheten att knyta an till annan forskning: att forskningsfrågan skall vara relevant för den beforskade gruppen ${ }^{1}$ och att impulser från utanför gruppen, t.ex. från den vetenskapliga litteraturen på området, inte skall ha särskilt stort inflytande på forskaren. Dessa aspekter tycks också vara bortglömda i ett antal studier som säger sig vara inspirerade av grounded theory. Layder (1993) konstaterar att grounded theory, genom sin kategoriska förnekande av värdet av annan än just grundad teori, kör in sig i en egen fålla där interaktionen med andra teorier omöjliggörs. Detta accentueras, enligt Layder, av kravet att teorin skall vara värdefull för den beforskade gruppen - detta gör det svårt, enligt honom, att använda allmänna vetenskapliga (sociologiska) koncept.

Denna kritik bör ses mot grounded theorys upphov som ett alternativ till de rådande sociologiska metoderna. Under årens lopp har den sedan blivit etablerad i mnormalforskning" - och det är då som problemen

1 I motsats till Wuest (1995) som konstaterar att grounded theory väl lämpar sig för feministisk forskning anser jag att inte bara min undersökning, utan en hel del feministisk forskning bli omöjlig att bedriva med hjälp av grounded theory på grund av detta - kön och makt upplevs ju inte alltid som det främsta problemet hos våra forskningssubjekt. med anknytning till annan forskning och relevans i forskarvärlden blir viktiga.

\section{Två utvecklingar av grounded theory}

Efter det att The Discovery of Grounded Theory kommit ut 1967, fortsatte Glaser \& Strauss att både utveckla metoden och att göra empiriskastudier med hjälp av den. Glasers Theoretical Sensitivity (1978) är nästa mer grundläggande utveckling av metoden. Efter det skildes Glasers och Strauss vägar åt - Glaser lämnade akademin under några år och Strauss etablerade sig på University of California, San Francisco, och inledde så småningom ett samarbete med Juliet Corbin. Nästa metodbok var Strauss Qualitative analysis for social scientists (1987) och sedan Strauss \& Corbin Basics of Qualitative research (1990), som blevStrauss' sista större bidrag till teoriutvecklingen. Till detta skrev Glaser ett svar, Basics of grounded theory analysis (1992). Senare har Glaser skrivit och editerat ytterligare böcker kring grounded theory $(1994,1995,1998)$.

Den svenska grounded theory -forskningen är ofta inspirerad av just Strauss \& Corbins praktiska handbok. Såväl avhandlingar som andra forskningsrapporter som anger sig ha en "gounded theory -approach" anger dem som sin referens, ibland tillsammans med Glaser \& Strauss, men utan att praktiskt taget någonsin nämna Glasers senare verk. Metodens vetenskapsteoretiska utgångspunkter diskuteras mer sällan (med undantag för Alvesson \& Sköldberg, 1994), utöver konstaterandet att grunderna ligger inom den symboliska interaktionismen. Det finns liten kunskap om att Strauss \& Cor- 
bins sätt att göra grounded theory inte är den enda, utan att det också finns, om än en liten, glaseriansk skola. ${ }^{2}$ Glasers senare arbeten upptäckte jag som doktorand nästan av en slump genom några artiklar i en amerikansk databas. Inom svensk kvalitativ beteendevetenskaplig forskning är det alltså i praktiken Strauss \& Corbins metod som numera betecknas som grounded theory.

Melia (1996) konstaterar att i engelsk forskning refererar man till Glaser \& Strauss (1967) som något slags grundval, möjligen till Glaser (1978) men att man fortsätter sedan med Strauss \& Corbin (1990) och att få är medvetna om Glasers arbete. Under senare delen av 90-talet har dock ett antal artiklar (Stern, 1994; Locke, 1996; Melia, 1996; Rennie, 1998) tagit sin utgångspunkt i Glasers variant av grounded theory och granskat närmare den metod som Strauss \& Corbin presenterar. I Sverige har Starrin m.fl. $(1991,1997)$ skrivit en grundläggande metodbok som enbart baserar sig på Glasers variant av grounded theory. Och efterStrauss bortgång 1996 har Glasers ställning som representant för grounded theory stärkts (Glaser 1999). Den nuvarande kopplingen av grounded theory till Strauss \& Corbin kommer alltså möjligen att försvagas i framtiden.

IMelias (1996) beskrivning kände jag igen min egen utveckling från att ha anammat Strauss \& Corbins (1990) version av grounded theory som visserligen detaljerad men användbar, till en upptäckt av Glasers kritik av den och en insikt i att Glaser i många

2 Glaser är numera verksam i »The Grounded Theory Institute", grundad och ledd av honom själv, www.groundedtheory.com. stycken har rätt i sina påpekanden. Melia beskriver hur hon under flertalet år hade undervisat om grounded theory, hur hon haft kontakter med Strauss och även förhandsläst vissa kapitel av Basics of Qualitative Research. Senare rekommenderade hon den för sina studenter, visserligen med viss tveksamhet, eftersom boken i hennes ögon ibland verkade väl detaljrik och teknikalistisk. I huvudsak var hon av uppfattningen att Strauss \& Corbin (1990) hade vidareutvecklat metoden från Glaser \& Strauss (1967)och enbart formaliserat och förtydligat den till förmån för nybörjare. Det var först efter det att hon läst Glaser (1992), där Glaser hävdar att Strauss \& Corbin inte presenterar grounded theory i sin ursprungliga form, utan en helt annan metod, som hon närmare började relatera Strauss \& Corbins bok till det som Glaser \& Strauss och Glaser publicerat om grounded theory, och fann att där faktiskt fanns ganska stora grundläggande skillnader.

Glasers Basics of Grounded Theory Analysis (1992) är helt tydligt en motbok till Strauss \& Corbins Basics of Qualitative Research (1990). I sitt anslag är boken inte akademisk - Glaser inleder med att redovisa sin brevväxling med Strauss inför utgivningen av Basics of Qualitative Research och sin irritation över att Strauss inte tagit hänsyn till hans protester när det gäller utgivningen av boken:

I request that you pull the book . It distorts and misconceives grounded theory, while engaging in a gross neglect of $90 \%$ of its important ideas...It indicates that you never have grasped what we did, nor studied it to try to carefully extend it. (Glaser, 1992, s. 2) 
Han fortsätter sedan genom att kapitel för kapitel gå igenom Strauss \& Corbins (1990) bok, och presenterar sina egna synpunkter till deras text, för att framemot mitten av boken mera ingående komma fram med sin grundläggande kritik: Strauss \& Corbin har förfalskat det som var grounded theory till den grad att en ny metod har uppkommit. Denna kallar Glaser (1992) "full conceptual description". Jämfört med grounded theory anser han att "full conceptual description" är onödigt arbetsam och krånglig. Men framför allt anser han att grundtanken i grounded theory, att teorin uppkommer från data, inte längre gäller i Strauss \& Corbins metod, utan att Strauss \& Corbin forcerar data in $\mathrm{i}$ forskarens egna tankeramar. Glaser motsätter sig alltså att Strauss \& Corbin använder beteckningen grounded theory för denna metod:

Anselm's methodology is one of full conceptual description and mine is grounded theory. They are very different, the first focusing on forcing and the second on emergence. The first keeping all the problems of forcing data, the second giving them up in favour of emergence, discovery, and inductive theory generation. (Glaser, 1992, s. 122)

Glasers (1992) motbok är personlig läsning, särskilt i förordet. Glaser skriver inte inom den vedertagna akademiska genren, utan uttrycker sin känsla av oförrätt och lämnar ut stycken ur sin privata korrenspondens med Strauss. Men bortsett från de personliga inslagen och sitt sätt att framställa kritiken för Glaser en relevant argumentation om bland annat forskarens roll och teknikaliteter i metoden så som den är presenterad av Strauss \& Corbin (Melia, 1996). Histo- rien om grounded theory, dess splittring och grenarnas fortsatta utveckling är kanske lika mycket en historia om hur den akademiska miljön fungerar, vilka individer har och inte har en röst och vilka beteenden och talarter som är acceptabla i denna kontext, som en historia om två mäns intellektuella framsteg när det gäller utvecklandet av en beteendevetenskaplig forskningsmetod.

\section{Vad gör forskaren i grounded theory - två uppfattningar}

Genomslagskraften av grounded theory kan tänkas vara förknippad med den lyckade kombinationen av dess upphovsmäns metodologiska skolor. Genom att sammansmälta en verifierande, kvantitativ tradition (Glasers bakgrund i Columbia University) med en öppen, explorativ, etnografiskt inspirerad fältstudietradition (Strauss bakgrund i Chicagoskolan) skapades en relativt strukturerad metod som kunde finna genklang hos kvantitativt skolade men kvalitativt inriktade sociologer. På det sättet är grounded theory ett ypperligt exempel på fördelarna av sammansmältandet av olika traditioner. Efter det att Glaser och Strauss gått skilda vägar verkar det dock som om deras respektive bakgrunder återigen gjort sig gällande i deras arbeten - vilket kanske är ett lika ypperligt exempel av tvärvetenskapens svårigheter, av att den akademiska socialisationen till en viss tradition är mycket stark.

Tydligast framstår skillnaden mellan Strauss \& Corbins och Glasers varianter av grounded theory när det gäller forskarens roll. Strauss \& Corbin (1990) uppmuntrar gärna forskaren till att gå till sina egna associationer och erfarenheter när det gäller data- 
analysen. Det är också denna aspekt som Glaser starkast kritiserar.

\section{Förförståelse}

I ursprungsversionen av grounded theory ser Glaser \& Strauss (1967) inte forskarens förförståelse som särskilt problematisk. Där finns en tilltro till att empirin talar med en egen röst och att de av forskarens förutfattade idéer som inte passar ihop med empirin inte kommer att kunna inkorporeras i den färdiga grundade teorin och därför kommer att falla av under processen. Visserligen anses en teoretisk eller empiriskbekantskap med det studerade området onödig och man avråder från uttalade eller outtalade hypoteser om vad forskningen kan komma fram till, eller vilka frågor som kommer att visa sig intressanta. Men detta anses snarare vara onödigt och komplicerande än en verklig risk för den grundade teorins validitet.

I Theoretical Sensitivity (1978) utfärdar Glaser kraftigare varningar mot den påverkan som forskarens förförståelse kan utöva på forskningsprocessen. Oerfarna forskare skall enligt honom som regel uppehålla sig inom sitt forskningsområde och den empiri som de direkt arbetar med, och impulser utifrån, som i och för sig kan vara värdefulla, skall endast fungera som inspiration. Samma gäller litteratur - läsning av tidigare forskning på området skall sparas till dess att forskaren redan har börjat att bygga en egen teoristruktur. Litteraturen skall alltid spela en underordnad roll och användas endast i den mån som den tillför något till det teoribygge som har sitt urpsrung i empirin. Glaser konstaterar även att forskarens halvfärdiga teoribygge nödvändigtvis ger rikt- ning åt hans fortsatta datainsamling, och att en forskare därför endast kan göra en studie inom samma område - fortsättningsvis är han alltid påverkad av sitt eget teoribygge.

Theory generation starts developing a perspective by which the analyst more and more sees his data and the concepts that emerge. He becomes trapped by his own emerging theoretical rhetoric. Thus an analyst is usually only good for one study in a given substantive field with a given focus. (Glaser, 1978, s. 48)

Här diskuterar alltså Glaser både förförståelsen, men också den förståelse som byggs upp i själva forskningsprocessen och som i viss mån styr den fortsatta forskningen.

Medan Glaser (1978) ser denna insnävning av forskarens intresse under forskningsprocessen som både nödvändig och problematisk, ser Strauss \& Corbin (1990) inte någon egentlig problematik, utan utfärdar sådana anvisningar för forskningsprojektets genomförande som grundar sig på just denna insnävning. De delar upp urvalsförfarandet när det gäller samlandet av empiri i tre faser: öppen datainsamling i samband med den öppna kodningen, selektivt urval när kategorierna och deras egenskaper och relationer börjar skönjas, för att fylla på dessa kategorier och klargöra relationer, och en mycket målinriktad datainsamling i slutskedet med ändamålet att validera den teori som börjar ta form. De är inte heller främmande för att forskaren i mellanfasen samlar in empiri från något område som inte direkt ansluter till det som är i fokus i forskningsprojektet. I princip ser alltså Strauss \& Corbin och Glaser en likartad process och insnävning av empirin, men det är enbart Glaser som i någon mån diskuterar den problematik som 
är förknippad med en metod där forskaren börjar bygga teori redan ur ganska fragmentariska empiribitar och där alltså dessa fragment, oavsett deras relevans eller representativitet, lätt blir styrande för den fortsatta forskningsprocessen och därigenom för hur den färdiga teorin kommer att se ut.

\section{Forskarens förhållningssätt $\mathrm{i}$ analysfasen}

Både Glaser (1978, 1992) och Strauss \& Corbin (1990) ser forskaren i analysfasen som ett instrument, men tycks mena tämligen olika saker med detta. Strauss \& Corbin går in för det subjektivistiska, tolkande perspektivet, där forskaren som instrument använder sin egen mänskliga erfarenhet för att förstå andra människor och använder sin mänskliga kreativitet för att uṇtäcka ickeuppenbara mönster och samband i empirin.

Strauss clearly identified the researcher as being actively involved with the method and not separate to the method. This subjectivist orientation is also discernible from the insistence of Strauss and Corbin that researchers using this method should draw on their experiential knowledge to collect data, for suggesting hypotheses, when analysing data, and more recently recognizing that the analyst is also a crucially significant interactant in the research process. (Annells, 1996, s. 387)

Glaser $(1978$, 1992) å sin sida vill se forskaren som ett objektivt instrument, som visserligen, som en mänsklig varelse, har en överlägsen förmåga att hitta mönster och samband i empirin, men vars förmåga just består av att genom hanterandet av empiri medelst en neutral metod komma åt möns- ter och samband som otvetydigt finns i den studerade verkligheten.

The tenet expressed by Glaser - that researchers should ascribe agency to the neutral methods they passively execute, constructing, as it were, a one-way mirror through which the natural world might be revealed - is consistent with the verificationist tradition in which hewas trainedat Columbia. Bazerman $(1988)^{3}$ refers to this as the active seeking of passive constraintsthat is, researchers actively seek to prevent and minimize their impact on the data through methods that restrain their influence....Clearly, in this tradition, the natural world is "out there" , and with an appropriate method executed with discipline and restraint, it will embed itself in theory. (Locke, 1996, s. 241)

Mot Strauss \& Corbins (1990) olika tekniker som de rekommenderar forskaren att använda för att locka fram mönster och innebörder i empirin, ställer Glaser (1992) sin uppfattning att det endast är kodning och kategorisering som krävs, att kärnan i teorin kommer att träda fram genom processen av kodning och kategorisering, helt enkelt eftersom teorin kommer att handla om informanternas centrala problem och därför inte kan förbli dold. Om forskaren börjar laborera med egna idéer finns däremot risken att informanternas centrala problem inte träder fram, utan att forskaren tvingar in data $\mathrm{i}$ sina egna konceptuella ramar, menar Glaser. Han är övertygad om att det finns mönster $i$ empirin och att dessa mönster kommer att uppenbaras för forskaren, bara hon gör sig

3 Bazerman, C. (1988) Shaping written knowledge: The genre and activity of the experimental article in science. Madison: University of Wisconsin Press. 
tillräckligt förtrogen men materialet genom att hantera det och att vara sensitiv till dess innehåll.

If you torture the data enough it will give up? This is the underlying approach in the forcing preconceptions of full conceptual description. The data is not allowed to speak for itself, as in grounded theory, and to be heard from infrequently it has to scream. Forcing by preconception constantly derails it from relevance. (Glaser, 1992, s. 123)

I stället för att närma data med frågor som vem, vad, när och hur mycket, vilket Strauss \& Corbin rekommenderar, vill Glaser (1978, 1992) hålla forskarens huvud öppet och vaksamt, så att det kan lägga märke till och registrera svaret på den enda, grundläggande frågan: Vilket är det underliggande problemet för denna grupp av människor och hur hanteras det?

I have hoped to save the student and the beginning user of grounded theory from all Strauss' rules and the fractured concepts so he or she can just get to the relevancy of what emerges and discover a theory that accounts for variation in the dependent variable: the main concern or problem. (Glaser, 1992, s. 99)

Det som är problematiskt med Strauss \& Corbins (1990) mer subjektivistiska metod är att de inte råder forskaren att tänka över sin förförståelse. I såväl hermeneutiskt som fenomenologiskt inspirerade analysmetoder är förförståelsen ett centralt problem, och dess inverkan på forskningsresultaten måste hanteras på ett eller annat sätt. I Strauss \& Corbins bok uppmuntras forskaren att använda sig av sin förförståelse, men utan råd angående hur hon skall förhålla sig till problemet att hennes resultat därigenom kommer att återspegla inte en objektiv utan en tolkad verklighet.

Även Glaser $(1978,1992)$ brister i kravet att förförståelsen skall redovisas - enligt honom är det ju till sist empirin som talar för sig själv, när forskaren har praktiskt hanterat det genom kodning och kategorisering tillräckligt länge. Glasers objektivistiska forskare kommer också fram till en tolkad verklighet, men spelrummet för hennes individuella förförståelse är mindre.

\section{Omvärldsfaktorer, strukturer och institutioner i grounded theory}

Grounded theory har kritiserats för att hålla sig till ett mikroplan och för att vara alltför partikulär (t.ex. Layder, 1993). Visserligen skriver Glaser \& Strauss år 1967 om hur övergripande, formella teorier kan utvecklas med grounded theory, men i praktiken har användarna av metoden begränsat sig till enstaka områden. Sätten att möta detta slags kritik kan vara att antingen försöka utvidga metoden och visa på att den även kan inkorporera mer övergripande fenomen, eller också att acceptera kritiken och konstatera att grounded theory visserligen bara lämpar sig för en variant av forskningsproblem, men att den därigenom ändå utgör ett värdefullt bidrag i sociologins metodarsenal. Strauss \& Corbin (1990) väljer den förstnämnda vägen, medan Glaser $(1978,1996)$ väljer den senare.

Principen om att endast se till det som finns i empirin som bas för teorin tillämpar Strauss och Corbin inte lika strikt när det gäller att ställa den i empirin grundade 
teorin i större strukturella sammanhang. De har introducerat en "conditional matrix", där den aktuella empirin och den uppkommande teorin relateras till vidare samhällsförhållanden. Hur empirin eller den empirinära grundade teorin skall relateras till vidare förhållanden, vilka förhållanden som är viktiga, vilka nivåer man skall relatera till, vilka aspekter man skall eller kan koncentrera sig på, anger Strauss \& Corbin (1990) dock inte med tillnärmelsevis samma tydlighet som de beskriver analysen av skeenden på mikronivån. Här tycks forskarens egna personliga eller möjligen teoretiska intressen vara avgörande för vad som blir medtaget. "Conditional matrix" ger snarare ett intryck av att vara något som man relativt godtyckligt ritar runt sin grundade teori när denna har kommit upp ur empirin än något som är en integrerad del i analysen.

Att enbart hålla sig till interaktionsplanet kan vara otillfredsställande, om det under forskningsprocessens gång framgår att olika slags ramar har stor betydelse för den studerade processen. Att då ha Strauss \& Corbins (1990) "conditional matrix» att ta till kan tänkas som en lösning. Men hur man från ett relativt förutsättningslöst funderande kring vilka kringfaktorer, på institutionell, lokal och global nivå, som kunde vara väsentliga för den studerade processen kommer fram till modeller som håller för en kritisk granskning berättar inte Strauss \& Corbin. De ger alltså återigen mycket svängrum till forskarens förförståelse.

Glaser för sin del uppmanar forskaren att hålla sig till det som hon hittar i empirin. Särskilt i More grounded theory methodology (1994) hävdar han att grounded theory inriktar sig på mellanmänskliga processer, till skillnad från de flesta andra sociologiska teorier som inriktar sig på institutioner och strukturer. Detta innebär att flertalet forskningsfrågor hamnar utanför grounded theorys domäner, vilket Glaser inte förnekar. I stället för han en argumentation för denna inriktningens förtjänster. Han supplementerar alltså inte metoden med ett nytt element som Strauss och Corbin gör, utan markerar han dess fokus och gränser.

\section{Glasers syn på Strauss \& Corbin: krångligt och ensidigt}

Förutom att Strauss \& Corbins (1990) metod enligt Glaser (1992) öppnar för forskarens godtycke, menar Glaser också att metoden är onödigt komplicerad. När det endast är kodning och kategorisering som behövs för att tecrin skall kommana att uppståà àv sig jjälv, varför ta på sig onödiga tekniker och vedermödor, frågar han.

\begin{abstract}
Strauss' method of labelling and then grouping is totally unnecessary, laborious and is a waste of time. Using constant comparison method gets the analyst to the desired conceptual power, quickly, with ease and joy. Categories emerge upon comparison and properties emerge upon more comparison. And that is all there is to it. (Glaser, 1992, s. 43)
\end{abstract}

Ett genomgående tema i Strauss \& Corbin (1990) är kodfamiljen conditions, contexts, strategies, intervening conditions and consequences. Strauss \& Corbin visar stegvis hur empirin kan hanteras för att anpassas till detta mönster och hur den grundade teorin till sist uppstår med hjälp av denna kedja. Enligt Glaser (1992) innebär redan begränsningen till denna kodfamilj att fors- 
karen tvingar empirin in $\mathrm{i}$ en förutfattad ram, i stället för att låta empirin själv visa vilka samband som är relevanta. I Theoretical sensitivity (1978), Glasers sista bidrag till grounded theory före dess splittring, räknar han upp ett flertal kodfamiljer, av vilka en, causes, contexts, contingencies, consequences, covariances and conditions, liknarStrauss \& Corbins modell. Som bokens titel antyder, anser Glaser att en sensitivitet för de mönster och samband som uppstår i empirin är en avgörande egenskap för en forskare, och därför är begränsningen till en enda kodfamilj enligt honom ett stort avsteg från principerna i grounded theory.

It is necessary for the grounded theorist to know many theoretical codes in order to be sensitive to rendering explicitly the subtleties of the relationships in his data. Some are standard and some are less so... Though never fully known (they are always emerging) the fullest range of theoretical coding possibilities give the grounded theorist a powerful approach to generation of theory. (Glaser, 1978, s. 72)

Strauss \& Corbin (1990) själva hänvisar till denna utveckling av metoden, som Glaser gjort femton år tidigare, men begränsar sig sedan till en enda kodfamilj. De utgår ifrån att denna kodfamilj alltid är relevant och uppmanar forskaren attsamla in data tills det finns tillräckligt med evidens för det innehåll som kategorierna conditions-contextsstrategies-conditions-consequencesharidet aktuella fallet, så att teorin kan byggas på dessa kategoriers innehåll och inbördes relationer. Glaser å sin sida hävdar att denna begränsning reflekterar Strauss personliga intresse för just den här sortens kategorier, snarare än vetenskapligt grundade bedömningar om denna kodfamiljs överlägsenhet.

\section{Slutsatser}

I det ovanstående tydliggörs skillnaderna mellan Strauss \& Corbin respektive Glaser på ett sätt som de förmodligen inte skulle uppenbara sig i ett praktiskt forskningsprojekt. Intresse för att förstå forskningssubjektens konstruktion och hantering av sin verklighet, teoretisk sampling, minutiöst granskande och kodande av data, och en koncis och koherent beskrivning och förklaring av en social process är fortfarande de praktiska gemensamma nämnarna och kännetecknen för båda varianterna av grounded theory. Men det finns en underliggande skillnad mellan Glaser \& Strauss (1967) respektive Strauss \& Corbin (1990) och denna skillnad blir synlig när Strauss \& Corbin jämförs med Glasers senare arbeten.

Vad som kallas och inte kallas grounded theory är naturligtvis en social överenskommelse, och inom den svenska beteendevetenskapliga forskningen är det vedertaget att Strauss \& Corbins metod har denna benämning. Däremot är det befogat att undersöka hur begreppet grounded theory, när man syftar på Strauss \& Corbin (1990), skiljer sig från den metod som presenterades av Glaser \& Strauss (1967) och Glaser (1978). Därutöver ger berättelsen om hur Strauss \& Corbins variant av grounded theory kom att dominera anledning till reflektioner om forskningens villkor i allmänhet: att det är avgörande från vilken plattform och hur man uttrycker sig för att bli hörd inom den akademiska världen.

Annells (1996) försöker placera grounded theory inom ett forskningsparadigm enligt Guba \& Lincoln ${ }^{4}$. Hon kommer fram

4 Guba, E. \& Lincoln, Y. (1994) Competing para- 
till att den ursprungliga grounded theory, liksom även Glasers variant från 1978, kan placeras inom det postpositivistiska paradigmet, medan Strauss \& Corbin kan placeras inom det konstruktivistiska paradigmet, även om de har vissa postpositivistiska drag. Enligt henne har faktiskt Glaser (1992) i sin ansats hållit sig närmare den ursprungliga grounded theory än Strauss \& Corbin (1990). Strauss \& Corbin har fört in ett tolkande perspektiv i grounded theory. Den ursprungliga metoden använde vissa tekniker på kvalitativt datamaterial, den manipulerade bitar av kvalitativt data på ett sätt som i visst avseende kunde jämföras med manipulerandet av siffror i statistiska undersökningar, för att framlägga samband och mönster bland dessa. Utgångspunkter var att allting fanns i empirin och att sambanden skulle uppenbara sig genom själva hanteringen. Strauss \& Corbin låter forskaren ganska fritt vandra utanför dessa ramar - enligt deras metod uppkommer resultaten inte av sig själva ur empirin, utan konstrueras av forskaren på grundval av empirin. Glaser \& Strauss visar på vissa positivistiska grundantaganden om forskaren som en neutral observatör och analyserare av ett insamlat datamaterial, medan Strauss \& Corbin, över två decennier senare, ger forskaren en friare roll som tolkare av data och konstruktör av resultat.

Men samtidigt avlägsnar sig Strauss \& Corbin från det som ursprungligen var styrkan i grounded theory och gjorde det möjligt för den att erövra en position i ett positivistiskt orienterat forskningsklimat: empirinär-

digms in qualitative research. I: N. Denzin \& Y. Lincoln Handbook of qualitativeresearch. Thousand Oaks: Sage. S. 105-117. heten, metodens neutralitet och (påstådda) stringens. En del av denna styrka går alltså förloradi deras variant. Samtidigt reflekterar inte Strauss \& Corbin över vad införandet av ett konstruktivistiskt perspektiv innebär för resultatens trovärdighet och debristeralltså $i$ en grundläggande förutsättning för ett forskningsparadigm där forskarens person explicit betraktassom en väsentlig del i forskningsprocessen.

Eftersom kodning och kategorisering i någon form är ett ganska naturligt sätt att hantera datamängder, är grounded theory något som är lätt att ta till, när man skall etikettera sin forskningsmetod. Men all kodning och kategorisering är inte grounded theory, varken i Strauss \& Corbins eller Glasers variant. Sådana frågor som forskarens totala öppenhet i början av forskningsprocessen, huruvida det är fråga om fenomen på den mellanmänskliga nivån eller huruvida resultaten är användbara för den beforskade gruppen är centrala i grounded theory. Dessa är frågor som flertalet forskare som angett sig använda grounded theory -approach hittills inte har reflekterat över. För en forskare som står inför ett metodval är det också viktigt att veta att, så som är fallet med de flesta etablerade kvalitativa forskningsinriktningarna, finns det fler än en variant att positionera sig bland, om man avser att använda grounded theory.

Och för att kunna föra mer grundläggande diskussioner om metodens potential och problematik behövs fortlöpande också mer grundläggande reflektioner om, inte enbart var metoden har sitt ursprung, utan också vilka antaganden om verkligheten, forskaren och forskningens ändamål dess olika former bygger på. 


\section{Litteratur}

Alvesson,Mats\&Sköldberg,Kaj(1994) Tolkningoch reflektion. Vetenskapsfilosofi och kvalitativ metod. Lund: Studentlitteratur.

Annells, Merilyn (1996) Grounded theory method: Philosophical perspectives, paradigm of inquiry, and postmodernism. Qualitative Health Research, 6:3, 379-393.

Glaser, Barney G. (1999) Keynote address from the fourth annual qualitative health research conference: The future of grounded theory. Qualitative Health Research 9:6, 836-845

Glaser, Barney G. (1998) Doing grounded theory: Issues and discussions. Mill Valley: Sociology Press

Glaser, Barney G. (red.) (1995) Grounded theory, 1984-1994. Mill Valley: Sociology Press

Glaser, Barney G. (1994) More Grounded Theory Methodology: A Reader. Mill Valley: Sociology Press.

Glaser, Barney G. (1992) Basics of Grounded Theory Analysis. Emergence vs Forcing. Mill Valley: Sociology Press.

Glaser, Barney G. (1978) Theoretical Sensitivity. Mill Valley: Sociology Press.

Glaser, Barney G. \& Strauss, Anselm L. (1967) The Discovery of Grounded Theory. Strategies for qualitative Research. Chicago: Aldine.

Guvå, Gunilla \& Hylander, Ingrid (1998) Att tillägna sig grounded theory. Fog-rapport; 43. Linköping: Linköpings Universitet, Institutionen för pedagogik och psykologi.
Layder, Derek (1993) New Strategies in Social Research. Cambridge: Polity Press.

Locke, Karen (1996) Rewriting The Discovery of Grounded Theory. After 25 years? Journal of management inquiry, 5:3, 239-245.

Melia, Kath M. (1996) Rediscovering Glaser. Qualitative Health Research 6:3, 368-379.

Rennie, David L. (1998) Grounded theory methodology. The pressing need for a coherent logic of justification. Theory \& Psychology, 8:1, 101-119.

Starrin m.fl. (1991) Från upptäckt till presentation: om kvalitativ metod och teorigenereringpå empirisk grund. Lund: Studentlitteratur.

Starrin m.fl. (1997) Along the path of discovery. Qualitative methods and grounded theory. Lund: Studentlitteratur.

Stern, Phyllis Noerager (1994) Eroding grounded theory. I: J.Morse (red.) Critical Issues in Qualitative Research Methods. Thousand Oaks: Sage.

Strauss, Anselm L. \& Corbin, Juliet (1990) Basics of Qualitative Research. Grounded Theory Procedures and Techniques. London: Sage.

Strauss, Anselm L. (1987) Qualitative Analysis for Social Scientists. New York: Cambridge University Press.

Wilson, Holly Skodol \& Hutchinson, Sally (1991) Pearls, pitch, and provocation. Triangulation of qualitative methods: Heideggerian hermeneutics and grounded theory. Qualitative Health Research, 1:2, 263-276.

\section{Summary \\ Glaser versus Strauss - two developments of grounded theory}

Grounded theory as a research method is presented in Sweden to practically all graduate students in behavioural and health sciences. Most often they read The Discovery of Grounded Theory by Glaser \& Strauss (1967) or Basics of Qualitative Research by
Strauss \& Corbin (1990). In this article some problematic aspects in Strauss \& Corbin's variant of grounded theory are compared with Glaser's development of the theory. The aim is to show that grounded theory is not an unambiguous concept, but that there are 
two parallel developmental processes, and that the development made by Strauss \& Corbin is problematic in some respects.

After having presented grounded theory in 1967 Glaser \& Strauss continued to develop the method and to use it in empirical studies. However, eventually their ways parted. Glaser left the academy for a number of years and Strauss established himself at the University of California. Together with Juliet Corbin he published Basics of Qualitative Research in 1990. To this Glaser wrote an opposition, Basics of Grounded Theory Analysis (1992).

ThisfarSwedish grounded theory research has been mainly inspired by the handbook of Strauss \& Corbin and, thus, the concept of "grounded theory" normally refers to their variant of the method. Glaser (1992) calls the method advocated by Strauss \& Corbin "full conceptual description", not grounded theory. This is mainly because, according to Glaser, Strauss \& Corbin try to force the data into the preconceptions of the researcher, instead of letting the theory emerge from the data. Glaser's book was not well received in the academic context, probably because of its personal and even aggressive tone.

The differences between Strauss \& Corbin and Glaser are most evident when the role of the researcher is considered. They also answer differently to the criticism that grounded theory is particular and unable to rise above a micro level. In addition, Glaser (1992) criticizes Strauss \& Corbin for making the method unnecessarily complicated and cumbersome, at the same time as it is more restricted than his own idea of grounded theory.

Because coding and categorizing in some form is quite a natural way to handle qualitative data, grounded theory often seems like a suitable label when one has to describe one's research method. But the total openness of the researcher when doing fieldwork, the practical usefulness of the results for the researched group, the interest in interactional process are examples of important features of grounded theory which many researchers have not reflected on, even if they state that they use a grounded-theory approach. And for a researcher who is to select a research method it is important to know that there is more than one variant of grounded theory from which to choose. To know the potential and the problems of the method one also needs to know the assumptions about reality, the researcher and the aim of research on which the different variants of the method are based. 